\title{
Urodimento
}

REVISTA DE ESTUDOS EM ARTES CÊNICAS

E-ISSN 2358.6958

\section{Prometendo a cena online como acontecimento: Uma análise de Tudo que coube numa VHS, do Grupo Magiluth}

\author{
Stephan Baumgärtel \\ Giórgio Zimann Gislon \\ Karine de Oliveira Cupertino
}

Para citar este artigo:

BAUMGÄRTEL, Stephan; GISLON, Giórgio Zimann; CUPERTINO, Karine de Oliveira. Prometendo a cena online como acontecimento: Uma análise de Tudo que coube numa VHS, do Grupo Magiluth. Urdimento - Revista de Estudos em Artes Cênicas, Florianópolis, v. 2, n. 41, set. 2021.

doi DOI: http:/dx.doi.org/10.5965/1414573102412021e0123

Este artigo passou pelo Plagiarism Detection Software | iThenticate 
Prometendo a cena online como acontecimento: Uma análise de Tudo que coube numa VHS, do Grupo Magiluth

Stephan Baumgärtel ${ }^{1}$

Giórgio Zimann Gislon²

Karine de Oliveira Cupertino ${ }^{3}$

\title{
Resumo
}

Este artigo interroga de que maneira estrutural e temática Tudo que coube numa VHS, do Grupo Magiluth, se endereça ao espectador dentro do contexto psicossocial de pandemia de Covid 19. Indaga como os traços formais e temáticos do trabalho se relacionam com modos atuais de sustentação do sistema capitalista através de relações sociais instáveis e subjetividades exacerbadas. Dentro desse escopo, o artigo analisa a oferta tecnovivencial feita por esse trabalho cênico online como exemplo de uma produção tensionada de pseudo-acontecimentos escapistas e acontecimentos transformadores.

Palavras-chave: Acontecimento teatral. Performatividade online. Representação online. Teatro na pandemia. Teatro online.

\section{Promising the online stage as event: an analysis of Tudo que coube numa VHS by Grupo Magiluth}

\begin{abstract}
This article analyses how structure and topics presented in the online performance Tudo que coube numa VHS by Grupo Magiluth address the spectator regarding the psico-social context created by the Covid-19 pandemia. It asks how these formal and thematic traits relate to unstable social relations and excited subjectivities as elements through which the capitalist system nowadays sustains its functioning. Within this focus, the article analyses the tecnocomunal proposal that designs this online performance as an example of a production of events and pseudo-events, molded by the tension between escapist and transformative gestures.
\end{abstract}

Keywords: Online performativity. Online representation. Online theatre. Theatrical

\footnotetext{
1 Pós-doutorado na Escola de Comunicações e Artes na Universidade de São Paulo (ECA/USP |2009-2010). Doutorado em Literaturas da Língua Inglesa pela Universidade Federal de Santa Catarina (UFSC - 2005). Mestrado em Letras Inglês pela Ludwig-Maximilians-Universität München (1995). Professor associado da Universidade do Estado de Santa Catarina na área de história do teatro, estética teatral e dramaturgia. (⿶) stephao08@yahoo.com.br

http://lattes.cnpq.br/8439378198120294

https://orcid.org/0000-0002-7769-1108
}

2 Doutorando em Teatro pela Universidade do Estado de Santa Catarina (UDESC). Mestrado em Artes em Estudos Latino-Americanos - Leiden University (2013). Mestrado em Literatura pela Universidade Federal de Santa Catarina (UFSC - 2015). 술. giorgiogislon@gmail.com

$9 \underline{\text { http://lattes.cnpq.br/3399458434426385 }}$ (iD https://orcid.org/0000-0003-3744-5305

${ }^{3}$ Graduada em Teatro pelo Centro de Artes da Universidade do Estado de Santa Catarina (UDESC). (ब. sptkarine@gmail.com

(9) http://lattes.cnpq.br/8076170573332170 
event. Theatre within the pandemia.

Prometer la escena online como acontecimiento: un análisis de Tudo que coube numa VHS, del Grupo Magiluth

\section{Resumen}

Este artículo investiga de que manera estructural y temática Tudo que coube numa VHS, del Grupo Magiluth, se dirige al espectador dentro del contexto psicosocial pandémico de Covid 19. Se pregunta cómo los rasgos formales y temáticos de la obra se relacionan con la forma actual de sustentación del sistema capitalista a través de las relaciones sociales inestables y subjetividades destacadas. En este ámbito, el artículo analiza la oferta tecno-vivencial que ofrece esta obra escénica online como ejemplo de una producción rellena de pseudo-acontecimientos escapistas y hechos transformadores.

Palabras-clave: Acontecimiento teatral. Performatividad online. Representación online. Teatro en la pandemia. Teatro online. 
Em meio à pandemia de Covid 19 que abalou os alicerces sócio-econômicos e psico-afetivos de grande parte da humanidade no ano de 2020, os artistas de teatro brasileiros escolheram buscar meios para continuar produzindo artisticamente e garantir nesse ato de resiliência sua sobrevivência. As possibilidades de criação por meio de plataformas digitais foram exploradas desde por artistas pouco conhecidos dos mais variados lugares do país até por grupos e companhias renomados. Nesse contexto, mais importante do que tentar resolver a questão paradoxal que surgiu no primeiro momento sobre a pertinência de nomear essas produções em plataformas digitais como teatro ou não4, consideramos ser o debate do campo teatral sobre as escolhas estéticas dos artistas que criam nessas plataformas Isso concerne, não por último, as maneiras como essas escolhas com suas mediações simbólicas implicam o/a espectador/a nesse processo performativo e atravessado não só por dimensões sensoriais, mas também ideológicas.

Para contribuir para esse debate escolhemos Tudo que coube numa VHS do Grupo Magiluth, por se tratar de uma criação que se propôs a utilizar as diversas redes sociais e plataformas digitais como portadores de uma estratégia dramatúrgica que pretende provocar no/na espectador/a uma relação de uma intimidade inusitada com os artistas e com o material cênico apresentado de forma online. ${ }^{5} \mathrm{O}$ fato de que, dentro dessa nova modalidade dramatúrgica, esse foi um dos trabalhos mais bem sucedidos junto a seu público, ${ }^{6}$ é outro aspecto

${ }^{4}$ O debate, na verdade, é mais antigo que a pandemia. O teórico argentino Jorge Dubatti (2015, 2018) diferencia convívio de tecnovívio, e afirma que o tecnovívio não é teatro, mas é uma forma de artes cênicas. Em todo caso, acreditamos ser mais frutífero discutir o alcance estético-político das realizações do que chegar a uma definição formal que se pretende conclusiva.

${ }^{5}$ Assistimos a essa proposta a partir da compra online do ingresso para a peça integrante da 27a edição do Festival Porto Alegre em Cena, de 2020, em horários diferentes entre os dias 25 a 27 de outubro de 2020. Sobre a intimidade inusitada, apresentamos ao longo do texto diversas citações dos artistas e da equipe de divulgação. SYMPLA. Página do evento 'Tudo que coube em uma VHS'. Disponível em https// www.sympla.com.br/tudo-que-coube-em-uma-vhs---2310---20h_988633 Acesso em: 11 nov. 2020.

${ }^{6} \mathrm{O}$ trabalho, conceituado como um "experimento sensorial em confinamento", iniciou sua temporada online entre os dias 07 a 31 de maio, de quinta a domingo, e realizou o que era por enquanto sua última temporada de 2020 entre os dias 04 a 15 de novembro, passando por uma temporada organizada pelo SESC Avenida Paulista e um convite para apresentar dentro do festival Porto Alegre em Cena. O sucesso do trabalho fez - grupo produzir uma segunda proposta, o Todas as histórias possíveis, que realizou sua segunda temporada em setembro de 2020. Disponível em https://www.facebook.com/magiluth/posts/tudo-quecoube-numa-vhs-experimento-sensorial-em-confinamento-um-trabalho-criado/1548813865273505/ 
que confere à montagem uma exemplaridade em relação a trabalhos feitos online durante a pandemia e uma dimensão sintomática no que diz respeito ao horizonte coletivo de expectativas simbólicas e afetivas de seu público. Certamente, para alcançar esse sucesso e garantir ao grupo uma sobrevivência financeira durante a pandemia, ${ }^{7}$ esse trabalho achou uma forma de responder a um anseio cultural e socialmente relevante.

As questões que gostaríamos de colocar como condutoras da nossa reflexão sobre Tudo que coube numa VHS dizem respeito aos modos como estrutura e temática do trabalho se endereçam ao espectador e como ambas respondem simbólica e estruturalmente, por um lado, à situação psicossocial durante a pandemia: o medo, o isolamento, a transformação do convívio social e a alteração na percepção do tempo. Por outro lado, indagamos como esses traços formais e temáticos se relacionam com uma força construtiva mais profunda e duradoura que a pandemia de Covid-19: o modo atual de produção capitalista que, entre outros efeitos, restringe nossa agência social coletiva, ao mesmo tempo em que nos relaciona por meio de um solipsismo, de uma competitividade instrumental; modo que aliena as pessoas dos aspectos mais orgânicos ou naturais de sua existência ao enquadrar as práticas sociais e profissionais num ritmo temporal cada vez mais frenético e fragmentado; e que distancia os seres humanos de ritmos afetivos de absorção mais lenta, além de oferecer o constante consumo de mercadorias (sejam elas objetos mesmo, práticas sociais padronizadas, tecnologias ou até identidades imaginárias) como panaceia comportamental para as faltas e riscos existenciais ou sociais decorrentes. ${ }^{8}$ Nesse contexto, autores como Slavoj Žižek (2011, 2017), ou Mark Fisher (2020) nos alertam que aquilo que

Acesso em: 19 nov. 2020.

Como afirma o ator Mario Sérgio Cabral, em entrevista ao Canal Arte1, o Grupo Magiluth foi um dos poucos grupos a conseguir sobreviver nesses tempos pandêmicos graças à venda de ingressos: "Com um trabalho feito para esse momento, a gente está vendendo bem.” Disponível em: https://www.youtube.com/watch?v=NyV9Hj_niRo\&ab_channel=CanalArte1, Acesso em 19 nov. 2020, posição 4'20". Os cinco atores do Magiluth atendiam, entre quinta e domingo, durante seis horas cada um a 12 pessoas. De modo que 240 pessoas assistiam o trabalho em cada semana, com preços de 20 reais por participação. Nessa entrevista, de junho de 2020, Mário Sérgio afirma que mais que 1300 pessoas já assistiram ou agendaram sua entrada, oriundos de mais de 20 países no mundo. "Nosso primeiro trabalho sem barreiras geográficas." (4'25 - 4’45”).

${ }^{8}$ A descrição fenomenológica mais difundida dessa realidade é certamente a fórmula da "modernidade líquida” de Zygmunt Bauman (2001). Para reflexões que conjugam análises sociológicas, antropológicas e estéticas, ver Fisher (2020), Jameson (1991, 1997, 2001) e Žižek (2011), sobretudo o capítulo Felicidade e tortura no mundo atonal do referido livro. 
se apresenta como uma constante invenção de novas formas sociais de relacionar-se por meios tecnológicos atualizados não passa de uma enorme instabilidade social e de uma excitação temporal e afetiva que assumem de fato o caráter de um pseudo-acontecimento constante ${ }^{9}$. É em relação a esse contexto que nos chamou atenção a conexão de Tudo que coube numa VHS com fenômenos que podem ser discutidos como acontecimentos.

\section{A proposta de vivenciar um acontecimento como elemento fundamental da estrutura de Tudo que coube numa VHS}

Provavelmente não há nenhum ser humano que já não acordou de seu sono com a nítida percepção de que esse sonho que ele acabou de vivenciar foi uma importante mensagem que convoca a mudanças e ao reconhecimento da possibilidade de realizá-las. Uma mensagem oriunda de uma dimensão de seu ser inacessível a sua vontade consciente, ou seja, um encontro com nossa alteridade dentro de nós mesmos. E, certamente, há um bom número de pessoas que já saíram de um cinema, teatro ou show musical ou até de um tempo de leitura abatidas pelo impacto das sensações que as atravessou e thes causou a impressão de não poder continuar ser a mesma pessoa que antes. Nesse caso, as diferentes manifestações artísticas exercem o papel de uma alteridade que nos faz perceber e desejar outras possibilidades para nossa vida. Alain Badiou nomeia esse encontro com uma possibilidade que irrompe dentro de nós como acontecimento, e explica que dele decorre um chamado de incorporá-lo no mundo:

Para mí, un acontecimiento es algo que hace aparecer cierta posibilidad que era invisible o incluso impensable. Un acontecimiento no es por sí mismo creación de una realidad; [...] Nos propone algo. Todo dependerá de la manera en que esta posibilidad propuesta por el acontecimiento sea captada, trabajada, incorporada, desplegada en el mundo. Eso es lo que yo llamo 'procedimiento de verdad' (Badiou, 2013, p.21).

É por causa desse aspecto de revelar algo até agora impensável que o

9 Trata-se de uma promessa de acontecimento, de alteração e renovação das regras do convívio social, mas que não passa de uma pseudo-fenômeno, pois não consegue produzir essa alteração. Apenas vampiriza o desejo das pessoas por uma alteração e transformação das relações sociais em que vivem. 
acontecimento comporta, para Badiou, um elemento de contingência. Žižek (2017, p.7) concorda com esse aspecto ao dizer que um acontecimento é caracterizado por produzir um "efeito que parece exceder suas causas - e o espaço de um acontecimento é aquele que é aberto pela brecha que separa o efeito das causas." Portanto, o modo de desdobrar o acontecimento no mundo não segue um caminho predeterminado, embora Badiou alerte para o fato de que um acontecimento verdadeiro nos confronta com a possibilidade de uma transformação do mundo na qual um interesse subjetivo e um interesse universal se juntam. ${ }^{10}$ Em princípio, entretanto, trata-se nesse desdobramento de um agir sobre o mundo no qual o sujeito decide o grau de fidelidade que ele quer ou que ele se vê capaz de exercer em relação ao "chamado" do acontecimento. Talvez não seja errado afirmar que os seres humanos se interessam pela arte tanto quanto por esses sonhos significativos de ares transformadores, porque esses fenômenos oportunizam vivenciar um acontecimento em suas vidas.

Para além dessa pressuposição geral, há sobretudo dois motivos para evocar esse conceito de acontecimento como horizonte crítico para uma discussão do trabalho Tudo que coube em uma VHS do Grupo Magiluth. Primeiro, as declarações dos artistas e do material de release de que se busca em e por meio desse trabalho uma proximidade fora do comum, um encontro com o/a espectador/a, e consequentemente a questão de como esse encontro se relaciona estruturalmente, em forma de procedimentos estéticos performativos, com a compreensão de que o termo "encontro" implica numa relação com uma alteridade, e assim com o fenômeno de acontecimento, tal como conceituado por Badiou. Além disso, encontramos as temáticas centrais do enamoramento, da duração do amor, da separação e da morte que atravessam a narrativa ficcional do trabalho e que são temas que se apresentam claramente na vida humana como questões de abrir-se para acontecimentos e de seguir seu chamado

${ }^{10}$ Badiou (2013a; 2013b) usa o exemplo do amor (em cada relação amoroso articula-se a dimensão universal do amor), mas Žižek (2011, p. 123- p. 130; p. 384 - 395) o segue, quando explica que os momentos de levantes revolucionários são acontecimentos que mobilizam uma paixão universal por um potencial universal da humanidade (na Primavera Árabe ou no Occupy Wall Street por exemplo). Parece que na visão desses dois intelectuais, um acontecimento abre uma realidade objetiva cujo potencial crítico e utópico evoca aspectos universais na vida humana. 
transformador.11

De maneira significativa, o momento atual da pandemia coloca em cheque a possibilidade de vivenciar a própria vida como acontecimento. Entramos nesse momento pandêmico como se fosse um acontecimento, para logo perceber que na maneira como a sociedade lida com ele, esse se assemelha mais a um congelamento da experiência temporal, ou a uma intensificação abrupta e brutal de uma normalidade social homicida interminável. Dessa maneira, a pandemia se apresenta como fenômeno que oscila entre acontecimento e pseudoacontecimento, entre impulso que clama por transformação e outro que provoca e encena apenas um ativismo de conformismo e assim um gesto normalizante.

À luz dessa situação, a questão é como esse trabalho artístico, feito em seu formato técnico para esses tempos pandêmicos, configura, incorpora em si mesmo e propõe desdobrar no mundo essa potencialidade de acontecimento, de encontro humano enquanto acontecimento. Como ele evoca a irrupção de uma alteridade, de uma transformação, em seu interior processual ou ficcional, e assim realiza (ou não) uma fidelidade para com o acontecimento evocado. Antes de entrar em detalhes acerca desses dois aspectos cênicos (performatividade e representação ficcional), vamos apontar concretamente alguns elementos que evocam o fenômeno do acontecimento como parte integral do tecido funcional e simbólico desse trabalho, aproveitando essa análise para apresentar a construção geral desse, conforme o subtítulo da peça, "experimento sensorial em confinamento".

O primeiro contato entre um dos atores do Grupo Magiluth e um/a espectador/a é feito pouco antes do horário marcado para o início da apresentação por meio de uma ligação telefônica. O artista se apresenta com seu nome social e se direciona a nós, nos chamando também por nossos nomes sociais. Nesta ligação ele nos convida para entrar numa "outra realidade", uma "realidade paralela"12, estabelecendo dessa maneira a costumeira linha divisória, como se

\footnotetext{
${ }^{11}$ Badiou (2013a e 2013b) usa em vários momentos o fenômeno de apaixonar-se e logo o de dar duração a essa paixão a Dois, para explicar o que quer dizer com acontecimento e com procedimento de verdade.

12 Os termos são usados em cada apresentação, também são usados no trecho que está no já referido vídeo
} 
fosse uma quarta parede, entre ficção e vida empírica, da mesma maneira que na relação teatral em espaços físicos quando se estabelece com essa separação também um convite para vivenciar uma presença compartilhada. Trata-se de uma proposta de identificação complexa, que reconhece a separação (entre realidade e ficção, entre ator e espectador), e que a partir disso instaura uma situação de intimidade cativante que, primeiro, aproxima o espectador do ator, e em segundo lugar, nos aproxima da ficção e nos convida a uma entrega dupla: à destreza composicional sensorial (sobretudo vocal) do ator enquanto narrador e ao encanto da ficção, essa "realidade paralela". Em ambos os casos, evoca-se uma possível entrega mais ou menos apaixonada à alteridade, a uma realidade parecida, mas diferente, ou seja, prepara-se a expectativa e a confiança de logo vivenciar uma apresentação cênica que se constituiria como acontecimento duplo - na dimensão performativa e na dimensão ficcional. ${ }^{13}$

Os próximos contatos são feitos pela plataforma do WhatsApp. Um vídeo em que um personagem fala em primeira pessoa e se endereça a um você é enviado diretamente para o/a espectador/a. Esse vídeo gera, nos primeiros segundos, a dúvida se ele se dirige a mim, o/a espectador/a, ou a um outro você ficcional. Na sequência do vídeo fica mais evidente ainda a busca da dramaturgia de instaurar um pacto performativo-ficcional: esse você é alguém que era próximo da figura filmada, e agora, com esse destinatário que o vídeo oferece, o/a espectador/a é convidado/a ou a identificar-se com esse você personagem e seu ponto de vista ou, mantendo uma posição de testemunha, relacionar-se com a composição ficcional, a "realidade paralela" como um todo, adotando um olhar mais estrutural. ${ }^{14}$ O uso ambíguo desse você produz uma oscilação importante na percepção do/da espectador/a entre personagem e observador/a, pois essa própria oscilação funciona como espaço de instabilidade perceptual. Sabemos 
desde as vanguardas modernistas, mas também pelos experimentos brechtianos, que essa instabilidade constitui potencialmente um acontecimento perceptual, no sentido de propor - contra a percepção habitual e padronizada de uma realidade objetiva e dada - que a realidade não passa de um fenômeno estético instável e que tanto a ficção quanto a performatividade cênicas, portanto, possuem uma força agencial pragmática.

Em outras palavras, o trabalho se baseia aqui numa disjunção entre realidade empírica e ficção, para quase simultaneamente questionar e seduzir-nos a uma identificação dominante com a ficção. ${ }^{15}$ Mas o próprio procedimento de enviar sequencialmente o material audiovisual sempre nos lembra dessa ficção como montagem performativa, ou seja, da disjunção entre performatividade e ficção. Uma dimensão pode funcionar como alteridade desestabilizadora da outra e o jogo entre ambos como experiência de alteridade para nossa percepção padronizada. ${ }^{16}$

Logo depois desse convite pessoal, antes ainda de entrar no campo das memórias desse personagem com o você amado, recebemos outro vídeo que serve como uma fundamentação ontológica das atribulações amorosas posteriores. Nesse vídeo, referenciado via WhatsApp com seu link no YouTube, uma voz em off, sob uma música elegíaca, faz um exercício explicativo de rememoração, afirmando que "[é] impossível dizer o que havia antes, como éramos, o que fazíamos, como olhávamos para as coisas," e, após uma longa enumeração de atividades cotidianas, avisa que "na verdade nada disso existia até o dia do estrondo, da explosão, da batida de átomos" que fez com que "daqui para frente, seríamos corpos voando pelos espaço [...] e ficando a cada momento mais distante um do outro"17.

\footnotetext{
${ }^{15}$ Para os produtores e meios de divulgação, o aspecto mais relevante (por ser o mais atraente) é claramente essa identificação com a história ficcional e o abandono de uma atitude distanciada e crítica. O SESC Avenida Paulista, por exemplo, enfatizou em sua divulgação a proposta de que "um dos atores faz com que você vivencie uma história como se fosse a sua". O próprio subtítulo "experiência sensorial" escolhido pelo grupo enfatiza o aspecto vivencial e identificador. Facebook. Perfil do Sesc Avenida Paulista. Disponível em https://www.facebook.com/sescavpaulista/posts/3037332699647334 Acesso em: 20 jul. 2020.

${ }^{16}$ Importante perceber que aqui não se afirma que não haja diferença entre realidade empírica e ficção, ou seja, em termos pós-modernos, que o mundo seja apenas “texto". A relação instável entre ambos, a força agencial de ambos, é a dimensão importante, o que garante a essa estrutura a potência de acontecimento também em contextos pós-modernos atuais nos quais a meta-ficção é muitas vezes empregada como um pseudoevento narrativo.

17 O vídeo está publicado no canal do ator do Grupo Magiluth Bruno Parmera no YouTube. Disponível em
} 
Esse texto e as imagens intergalácticas que o acompanham localizam o motivo fundamental da sensação de isolamento não num fator pandêmico, nem num arranjo socioeconômico específico, mas na condição humana existencial: fruto de um acontecimento de separação radical, na consciência de nossa individualidade, somos como esses átomos. O nascimento do eu e do mundo, da relação sujeito e objeto como uma relação marcada pela disjunção, é consubstancial. Trata-se de uma versão secularizada da fundamentação teológica da vida humana sob os efeitos da queda ${ }^{18}$. Com o antes paradisíaco inacessível pode surgir a consciência humana, o que instaura a vida como uma cena de luta possível contra os efeitos da separação (mas também de sua aceitação). Ou seja, a queda torna possível o desejo e o amor.

Tanto a vida amorosa e sexual quanto a atividade simbolizante podem ser vistas como expressões dessa simultaneidade dentro de nós. A instauração da consciência de levar uma vida "cada momento mais distante um do outro" é o acontecimento da separação ou da negatividade (em seu sentido filosófico) que se desdobra na percepção do/da espectador/a. É a pressuposição lógica e a preparação afetiva para poder vivenciar intensamente o que Badiou (2013b) chama o encontro da cena do Dois, a atração de dois seres que suspendem (mas não superam definitivamente) num esforço constante a entropia da disjunção. ${ }^{19}$

Ou seja, a referida rememoração de um acontecimento (nesse filme, o da "explosão e batida de átomos") salienta a possibilidade de viver esse

https://youtu.be/ccLZYCuhUmA Acesso em: 9 dez. 2020. Ver 0'03" - 1'52".

\footnotetext{
18 Žižek dedica um capítulo de seu livro Acontecimento à queda como acontecimento não só no campo religioso, mas também científico e sobretudo semiótico, articulando a entrada do universal e informe no tempo das particularidades e formas específicas: "O principal acontecimento é a própria queda, a perda de uma unidade e uma harmonia primordiais que nunca existiram, que são apenas uma ilusão retroativa. O fato surpreendente é que esse tema do acontecimento também ressoa fora do campo religioso, na versão mais radical da ciência de hoje, a cosmologia quântica [...]: coisas surgem quando o equilíbrio é destruído, quando algo dá errado" (2017, p. 31 e p.32).

19 “Temos no amor um primeiro elemento que é uma separação, uma disjunção, uma diferença. Temos um Dois. [...] O segundo aspecto é que, justamente por tratar de uma disjunção, no momento em que esse Dois vai se mostrar, entrar em cena enquanto tal e experimentar o mundo de um jeito novo, ele só pode assumir uma forma aventurosa ou contingente. É o que chamamos de encontro. [...] E a esse encontro atribuo o status [...] de evento, ou seja, de algo que não se insere na lei imediata das coisas. [...] O amor não é simplesmente o encontro e as relações fechadas entre dois indivíduos, e sim uma construção, uma vida que se faz, á não mais pelo prisma do Um, mas pelo prisma do Dois. E é isso que chamo de 'cena do Dois"” (Badiou, 2013b, p.23-24).
} 
acontecimento novamente, não para resignar-se com o distanciamento crescente, mas para tirar da repetição desse afastamento no interior da performance narrativa uma força pulsante para a vida presente, ao menos para esse presente em que a apresentação durar. Essa força pulsante pode vir da radicalização dessa negatividade do encontro explosivo ou das tentativas de sua suspensão, constantemente reencenadas. A atração acontecimental do trabalho se dá em grande parte pela oscilação entre as duas possibilidades: negatividade da vida/morte e afirmação positiva/amor.

Não surpreende, então, que logo estamos sendo levados para os episódios da relação amorosa ficcional entre o narrador e o personagem você. O material visual e os áudios enviados via WhatsApp recebem agora datas mais concretas, mas numa ordem não sequencial, e cobrem um tempo entre novembro e abril/maio, possivelmente estendido ao longo de dois anos. Não sabemos por certo, pois não recebemos os anos para as datas, mas como o primeiro vídeo (que já anuncia a morte do narrador ou de seu próprio personagem) é datado de 07/05, e outro material audiovisual referente ao desenvolvimento da relação recebe datas, entre outras, de 09/07, de 25/04 e de 08/11, sendo que os últimos momentos documentados da relação dizem respeito aos dias 25 e 26/04, concluímos que a relação de fato terminou em abril. Mas o jogo temporal aqui nos parece secundário, mesmo que essa ordem não-linear das memórias possa ser interpretada como uma representação intencional para evocar o próprio processo de lembrar-se como acontecimento: lembrar-se é sempre em boa parte uma reinvenção. Mais importante parece ser o fato de que esses episódios documentam um drama, i.e., o processo de apaixonar-se e dentro dele uma lenta, mas gradual abertura de um para o outro. Ou seja, evoca-se o acontecimento do apaixonar-se e o comprometimento (em graus diferentes) dos dois personagens para com esse acontecimento inaugural de seu amor. Ou, em palavras de Badiou (2013, p.21): “Na verdade, existe a meu ver o encontro de um outro, mas, aí é que está, um encontro não é uma experiência, é um acontecimento que permanece inteiramente opaco e só tem realidade em suas consequências multiformes num mundo real”.

Numa linguagem visual-oral confessional, os episódios desenvolvem em uma bela simplicidade cotidiana essas consequências tal como se apresentam para 
esses dois amantes. Certamente cumprem com uma das tarefas e potências mais relevantes do amor que é, para Badiou (2013, p.43): "mostrar que existe de fato uma força universal do amor, mas que essa força é simplesmente, para nós, a possibilidade de realizarmos uma experiência positiva, afirmativa e criadora da diferença”. Os episódios realizam, então, ao menos parcialmente, para o fenômeno do amor o que Badiou, em relação ao acontecimento, chamou de procedimento de verdade: o conjunto de ações que buscam mostrar-se fiel ao acontecimento inaugural desse comprometimento mútuo na cena do Dois. Entretanto, há também nas lembranças (e não só no processo de lembrar) um movimento de controlar essa paixão e de certa maneira de comodificar a si mesmo e a esse outro, de tornar a pessoa um espetáculo, por exemplo, quando os encontros são propulsionados pela troca de sequências de fotografias.

Por último, nos deparamos com o sumiço do narrador amado, sua morte (real ou simbólica, suicídio ou acidente de modo que o primeiro vídeo é ou um tipo de mensagem pregravada ou uma volta espectral da figura amada), anunciada desde o início a ponto que aquilo que poderia ser o acontecimento mais impactante se torna quase um anticlimax. Sobretudo porque é representado por um áudio que não consegue chegar ao seu destinatário e que fica condenado a uma existência fantasma na caixa postal de um celular. Mas como o vídeo inicial anuncia que a apresentação dos episódios com seu material audiovisual deve servir quase como um ritual de despedida para que esse outro, o você, possa sentir novamente a própria vivacidade, há ainda outra mensagem necessária que redime ambos dessa situação espectral e cumpre com o objetivo revitalizante. Essa intenção surge quase como objetivo principal do trabalho na postagem final, já após do envio dos agradecimentos finais, - de certa maneira como uma moldura de antiacontecimento - quando o ator empírico, por meio de seu Instagram, nos informa que chegou bem e ficou sem sinal de celular, além de um link para o vídeo da música It's okay da banda Land of Talk que o você teria mencionado para ele. Um recado final que ostensivamente atenua o impacto frustrante ou doloroso tanto da separação ficcional dos protagonistas quanto do fim abrupto do contato com o ator enquanto mestre de cerimônias da narração, ${ }^{20}$ mas que também estende o

${ }^{20}$ O recado enfatiza a importância do título da música, ao repetir três vezes “É isso...tá tudo bem! Está Tudo 
enigma e a banalidade dessa separação à vida empírica. Dessa forma, o uso dessa música nos sugere que a morte do início fosse um truque retórico, um modo de falar, ou a retórica fosse um truque para evitar um dissenso entre a personagem ficcional e o você acerca do impacto doloroso desse sumiço. Como se esse você e nós espectadores junto com ele não devêssemos encontrar respaldo no material do trabalho quando queremos insistir que "por fim a um amor é sempre desastroso, até quando se aceita ou inclusive deseja esse desastre" (Badiou, 2013b, p.72). ${ }^{21}$ Uma atenuação da dor que se encontra também na linha do post scriptum desse recado que é apenas superficialmente consolador: "Tem histórias que nunca tem fim...". Acrescentemos, entretanto, a partir de ensinamentos psicanalíticos, que essas histórias que nunca tem fim são aquelas que a imaginação do sujeito não quer (ou não pode) terminar, por conter em si um conteúdo não-resolvido. Caso contrário, seria uma outra história com os mesmos personagens envolvidos.

Esse recado, então, é um último aviso sintomático de que, em relação à oscilação entre o empírico e o ficcional, mesmo após declarar que "está tudo Bem", ainda não se saiu do campo de forças da realidade ficcional paralela, embora essa leitura num primeiro momento contradiga a mensagem da música. Pois o envio dessa música It's okay pode ser lido também como sintoma confessional de que a relação não é bem terminada, de que ainda é necessário se convencer. E de que essa persuasão é a função principal da realidade paralela de cujo campo de força o espetáculo de fato não nos quer liberar.

Há duas soluções possíveis para essa contradição. A primeira seria aceitar a proposta da vida paralela e conformar-se na própria vida com a experiência do abandono e do "tudo bem". E a segunda seria elaborar no mundo empírico uma repetição-rememoração (por meio da criação de um acontecimento igual, mas que ganha outro rumo) que liberta esse você da dor traumática da separação ou da morte da pessoa amada como também do fim abrupto do trabalho cênico

Bem Está tudo bem". Disponível em https://www.instagram.com/p/Bn4reQqBl6c/?igshid=zllrkk88zm1y Acesso em: 26 nov. 2020.

${ }^{21}$ Žižek vai chamar esse processo de atenuar os choques da paixão uma tendência cultural de "renormalizar a violência de se apaixonar, a violência simpaticamente indicada por um termo basco - maitemindu -, que, literalmente traduzido, significa 'ser ferido pelo amor'” (2017, p.47). Sustentamos que esse trabalho do Magiluth evoca essa ferida, mas ele mesmo não a expõe nem a realiza seja em sua performatividade seja em sua camada ficcional. 
enquanto acontecimento. Nessa interpretação, o vazio relacional que o trabalho não consegue (e talvez nem queira) superar estimula a percepção de que é necessário e possível criar na vida empírica dos/das espectadores/as um outro acontecimento, outra explosão inicial. Esse evento retomaria a sensação de abandono afetivo e do controle do acontecimento no interior da vida paralela para na própria vida reencenar essa estrutura e dar a ela um outro rumo.

Seja como for a percepção de cada um/a sobre esse chamado "utópico" do trabalho, não temos dúvida que o impacto instigante da proposta está relacionado ao modo como evoca e inscreve, em seu processo de apresentação e de ficcionalização, os traços de diversos acontecimentos. Evocar-los atende, no mínimo, a um anseio por transformação e, no caso dos acontecimentos amorosos, simultaneamente, por uma cumplicidade: entre ator e espectador, entre narrador e espectador implícito, entre os personagens num processo de identificação. Elementos bastantes ausentes para quem vive os efeitos de uma quarentena prolongada.

Nesse contexto, não parece casualidade que Tudo que coube numa VHS se endereça ao espectador em três níveis diferentes nem sempre claramente separáveis: num nível que pertence à vida empírica (a relação ator - pessoa empírica) que forma uma espécie de moldura da apresentação; outro nível que pertence ao processo de narrar uma história, ou seja à performatividade do trabalho (narrador - espectador implícito) e um terceiro nível que pertence à ficção (personagem 1, denominado 'eu' - personagem 2 denominado 'você'). Três níveis que correspondem àquilo que podemos chamar de três tipos de acontecimentos artísticos: validar a vida empírica como obra de arte, validar a experiência estética de uma diferença relacional entre ambos, o que constitui uma potência de hibridez oscilante entre eles s, e validar o esquecimento da vida empírica numa obra de arte, construir a experiência estética como refúgio. Correspondem a esses três níveis de interação ou endereçamento (empírico, empírico-performativo-ficcional, e ficcional) três propostas de identificação e engajamento afetivo e crítico por parte do/a espectador/a: engajar o espectador afetivamente num ambiente social empírico; estabelecer performativamente um espaço híbrido no qual realidade empírica e mundo ficcional se interseccionam 
num aqui e agora cênico; e marcar a separação entre esse ambiente e o espaço ficcional, conduzindo a atenção para esse mundo ficcional e fixá-la sobre ele.

Como mostramos, o trabalho se engaja a evocar acontecimentos em cada uma dessas três dimensões, como se não houvesse contradições insuperáveis entre eles (como por exemplo entre o engajamento e o escapismo da primeira e da terceira dimensão). Nas configurações performativas e ficcionais escolhidas, encontramos simplesmente maneiras diferentes de lidar com a separação e de buscar possibilidades, por meio de diferentes acontecimentos na estrutura do trabalho, de "que o mundo possa ser encontrado e experimentado de outra forma que não seja por uma consciência solitária” (Badiou, 2013b, p.30). Não é só por isso que "amamos o amor", mas é também por isso que amamos (quando amamos) Tudo que coube numa VHS.

Entretanto, será que o trabalho de fato entrega uma fidelidade para com o acontecimento, por meio de seus "procedimentos de verdade" ficcionais e performativos? Por que motivo, a dramaturgia termina o espetáculo com esse fim curiosamente tímido? Dando impressão de não querer radicalizar a experiência do acontecimento, mas sobretudo consolar seus espectadores em relação às incertezas, carências e instabilidades de sua vida. Nas próximas duas seções deste artigo, vamos analisar e interpretar esses dois procedimentos, de verdade ficcional e de verdade performativa, mais a fundo.

A performatividade cênica como condução individual para uma proximidade, ou: de que encontro entre ator e espectador estamos falando?

O site de venda de ingressos para o Festival Porto Alegre em Cena 2020 descreve o trabalho da seguinte maneira:

Em "Tudo que coube numa VHS", o público é conduzido por um percurso em que se torna cúmplice das memórias de um personagem, cristalizadas em torno das recordações sobre um relacionamento. A ação é acompanhada via web, por meio de uma série de plataformas virtuais de comunicação e entretenimento, numa experiência individual que 
transporta a uma nova esfera as relações de proximidade entre ator e espectador, recorrentes na obra do Grupo Magiluth. ${ }^{22}$

Embora essa descrição não evoque explicitamente uma proposta participativa ou interativa - no sentido, por exemplo, de possibilitar uma conversa e assim uma invenção conjunta das memórias dessa personagem, pois fala em um "público conduzido por um percurso" que o dá acesso às memórias de um personagem - ela não obstante suscita algumas expectativas no "público" em direção a uma participação especial. A descrição promete uma experiência até certo ponto singularizada, pois, enuncia construir "uma experiência individual que transporta a uma nova esfera as relações de proximidade entre ator e espectador" (e não narrador e espectador implícito). A questão que surge aqui é até que ponto essa proximidade entre ator e espectador, num espetáculo em que uma pessoa se dirige "pessoalmente" a outra, evoca e consolida uma experiência de reciprocidade e de alteridade. As formulações do release e dos atores do grupo ${ }^{23}$ provocam questões como: será que se trata de uma cumplicidade sobretudo performativa ou as artimanhas performativas desses atores ao utilizar plataformas online visam nos convencer da realidade de uma cumplicidade ficcional, fundada na ficção das memórias do personagem? Como se articulam a padronização do material, a singularização de sua apresentação e a almejada singularidade enfatizada da recepção? Essas questões e suas respostas obviamente giram ao redor do uso do pronome você como exemplo do duplo endereçamento cênico e seu correlato, o duplo endereçamento do espectador, por meio da performatividade processual e da representação ficcional.

Ora, a expectativa de uma proximidade empírica-performativa, entre ator e espectador/a, é intensificada antes mesmo do acontecimento do evento. Logo após a compra do ingresso somos contactados pelo grupo para passar algumas informações pessoais, como nome e sobrenome, cidade e estado de residência, e 
telefone; além de contas em plataformas online (WhatsApp, Spotify ou Deezer, Instagram). Entretanto, durante a realização de Tudo que coube nessa VHS, ao longo do envio do material, a possibilidade de dialogar com o ator por meio do avatar "você" ou enquanto pessoa real e a potência dessa troca são mínimas. Mesmo que a gravação e o envio direto em tempo real de boa parte do material audiovisual contribua para manter a sensação inicial de intimidade cativante, de uma performatividade e presença compartilhada, ficamos de fato presos numa espécie de recepção solitária: já não temos como chegar perto do ator, e tampouco podemos assistir à experiência como público, como fenômeno coletivo. A proximidade viva, um encontro vivo, seja com o ator enquanto narrador ou com o ator enquanto pessoa empírica, é reduzido a mínimas respostas sem força agencial ou dialógica. Praticamente só espiamos o material a partir de uma perspectiva cujo controle está na mão do ator-narrador. A questão que surge, na medida em que os próprios artistas e não só o material de release de um festival falam em "encontro" com o espectador, ${ }^{24}$ é: que tipo estrutural de encontro o trabalho nos propõe? Que concepção de encontro surge na maneira como ele articula proximidade e separação, condução e abertura, não no interior da ficção sobre uma relação amorosa relâmpago, mas, antes, na configuração da interação entre artista e espectador, ou entre narrador e espectador implícito?

Nesse contexto, vale lembrar que propostas artísticas de proximidade entre um/a artista e um/a espectador/a já tem um histórico. No Brasil, desde meados da década de 90 há a prática de ações experimentais intituladas comumente de um para um. Nesse formato, a partir de diferentes meios e sem necessidade de uma copresença espacial (por exemplo, via ligação telefônica, tão possível para essa pausa mundial no teatro presencial), artistas convidavam participantes para um experimento que aconteceria somente entre artista e pessoa convidada, sem incluir uma plateia maior. Alguma situação era colocada entre um ator usando nome social ou como personagem e um espectador que, juntos, teciam um encontro a partir de algumas circunstâncias dadas. Apesar dessas ações terem

${ }^{24}$ Em sua página no Instagram, no dia 04 de maio de 2020, o grupo anunciou o espetáculo dessa maneira: "A gente não tá se aguentando de saudades de todxs. Para amenizar um pouquinho esse sentimento, resolvemos criar um trabalho novinho, feito para encontrar com vocês, de alguma forma, em tempos de pandemia. Disponível em https://www.instagram.com/p/B x7C6jnKZC/?utm_source=ig_embed Acesso em: 17 dez. 2020. 
estrutura, procedimentos, tempo e espaço muito diversos, alguns fatores são comuns entre elas, tais como pensar o público sendo co-autor do fazer artístico, a primazia do processo sob o produto e o borrar das fronteiras entre vida e arte. ${ }^{25}$

Sobre o primeiro ponto, é importante destacar que o um para um considera a participação do público não somente uma participação psíquica, mas uma cooperação de agência que possivelmente (sendo essa a esperança ou intenção) estabeleça uma obra enquanto acontecimento. Esse formato não apenas tem intenção, mas só acontece, de fato, caso a pessoa participante realize alguma ação que intervenha no resultado artístico: ela precisa ser também uma agente da obra. Já o segundo fator comum entre ações um para um atenta que toda ação desse tipo não cria um produto como sua finalidade principal. São encontros efêmeros, podendo se valer de registro, mas a obra em si é configurada no encontro, ela é o próprio encontro entre os sujeitos participantes entendido como acontecimento, uma "situação-obra". De fato, nessa abertura à intervenção do outro, o um para um se coloca como busca de possibilidades poéticas para instaurar a arte como acontecimento. No terceiro quesito, esse tipo de ação faz um desarranjo das camadas arte e vida, pois esse convite não solicita à pessoa um personagem, mas sim, nós mesmos enquanto sujeitos da vida cotidiana. Nessa concepção, Tudo que coube numa VHS claramente não é uma proposta de um para um, embora superficialmente lance mão de alguns traços ou vestígios desse formato.

Não se trata de oferecer um acontecimento cooperativo, em sua modalidade mais confrontativa ou mais harmoniosa, no meio de uma sensação de instabilidade, de perigo, de efemeridade, oriunda ou do modo de apresentação ou da ficção em si. ${ }^{26}$ O funcionamento do trabalho revela que a proximidade de fato não é vista como encontro, como cena do Dois que opera uma atração na instabilidade.

Portanto, onde o referido material publicitário afirma uma cumplicidade entre ator e espectador, deveria ter sido colocado: "entre narrador e espectador". Sem

${ }^{25}$ Para exemplos e análises concretas, ver: Um para um: a busca por uma subjetividade dialogada. Cupertino (2018).

${ }^{26}$ Mas não seria o operar na instabilidade, exatamente uma das características tanto da paquera quanto do relacionamento amoroso mais longo? 
dúvida, essa relação é habilmente organizada para fazer surgir a força afetiva da composição ficcional, seu magnetismo identificatório, seu encanto afetivo. Isso, entretanto, implica que a hibridez processual não pode ser usada para problematizar ou até quebrar o pacto identificatório. O que não se entrega é uma quebra performativa com esse magnetismo, com o reconforto afetivo. Ou seja, a dimensão de acontecimento não pode ser entregue em sua totalidade, essa dimensão é prometida para depois ser abandonada, como são abandonados o espectador no final do espetáculo e o você ficcional pelo sumiço/morte do amante.

Nesse sentido, mais do que aprofundar a dimensão de acontecimento, o perigo delicioso e aterrorizante de um diálogo libidinal feito por atração psíquica sem contrato preestabelecido no qual a "batida" dos átomos (humanos) os faz oscilar entre atração e dispersão, ${ }^{27}$ a performatividade do trabalho encena um controle desses impulsos. Seria apenas a partir do gesto de assumir o risco de vivenciar, na performatividade do trabalho, a "explosão, a batida dos átomos" que a proximidade (agora realmente dialógica) poderia surtar um efeito qualitativamente transformador. ${ }^{28}$

Dessa maneira, o procedimento de evocar uma hibridez performativaficcional, lembra um teatro representacional que coloca em segundo plano (ou usa como apartes ornamentais) a própria teatralidade inerente; a usa sobretudo para capturar a atenção do espectador e direcioná-la à ilusão ficcional sem que se problematize ou explore, para fins de crítica e esclarecimento, os procedimentos intrínsecos de sua construção. Em outras palavras, o Grupo Magiluth se coloca como um conjunto de contadores de histórias que habilmente

\footnotetext{
${ }^{27}$ Essa seria de fato a experiência sensorial que faria jus à nova esfera de relações na proximidade entre ator e espectador/a: a experiência de construir uma relação sem chão estabelecido, em cujo tecido relacional transparece constantemente essa ausência de uma solidez. E essa é a proposta do um para um enquanto formato cênico. Seu equivalente no campo da ficção seria uma ambiguidade inelutável que não se submete de antemão a um contrato mental conciliador entre ambas as partes, mas que revelaria constantemente a tensão entre o engajamento interpretativo e a opacidade tanto do material quanto dos sujeitos. Ou seja, as duas temáticas evocadas na história ficcional do trabalho: impulso amoroso e impulso de morte.

${ }^{28}$ O regulamento de apresentações (ou seja, de encontros) de trinta minutos é outro elemento conservador. Como modelo alternativo podemos pensar na duração de sessões de terapia lacaniana cujo tempo é marcado pela possibilidade do analisando liberar conteúdo relevante e não por uma duração mecanicamente estabelecida. Sobre esse assunto, ver Lacan, Jacques. O tempo lógico e a asserção de certeza antecipada. In: Jacques. Lacan. Escritos. Rio de Janeiro: Jorge Zahar, 1998.
} 
evoca em sua dramaturgia acontecimentos processuais possíveis. Assim, usa de maneira "quente" os aparatos "frios" da comunicação online. Entretanto, a fidelidade para com esses acontecimentos performativos é limitada e conduzida para configurar uma proximidade que apenas evoca o risco da cena do Dois, para, de fato, se oferecer ao desejo pela reconfortante cena do Um, mesmo que ela seja, em boa parte, assumidamente uma ilusão.

\section{Os afetos do medo da morte e da paixão pelo encontro amoroso como material da proposta de um acontecimento ficcional}

Vimos que no campo da performatividade aqui e agora não se articula uma fidelidade com o acontecimento inicial, a ligação do ator empírico. O encontro do Dois é evocado e logo deslocado para o campo da ficção no qual nós dois, ator e espectador/a empírico/a, entramos para tornarmo-nos função narrativa: narrador e espectador implícito. Cada envio de um áudio ou de um vídeo é um convite renovado de entrar nessa realidade ficcional paralela, intensificada - isso sim pelo uso performativo "ao vivo" das plataformas no aqui e agora. ${ }^{29}$ Como numa contação de história, a ficção é apresentada para que nela invistamos nosso desejo por um atravessamento surpreendente numa presença compartilhada. Com cada clique sobre um áudio e vídeo estamos renovando nossa expectativa e nossa fé na verdade e na relevância dessa realidade paralela. Mas como já sugerimos, as memórias são estruturadas de tal maneira a mostrar como nessa história se tenta minimizar o risco de viver as dimensões dolorosas, fragilizadoras de uma paixão.

\footnotetext{
29 Diferente de uma proposta como a de Amor de Quarentena (trabalho da MUK Produções, direção de Daniel Gaggini, autoria de Santiago Loza, disponível em http://amordequarentena.com/ Acesso 08 nov. 2020. Ver também propaganda da proposta no Sympla: https://www.sympla.com.br/amor-de-quarentena 933338. Acesso 08 nov. 2020. A proposta, de acordo com as mensagens recebidos entre os dias 16 e 28 de novembro, apresenta um produto totalmente enlatado, e por isso pode disparar para seu público cadastrado seis, sete mensagens de texto, áudio e vídeo em meio segundo várias vezes ao dia. A proposta do Grupo Magiluth, por outro lado, possui elementos que são pré-gravados, como os vídeos e imagens de Youtube e Instagram ou as músicas de Spotify, mas também áudios que estão sendo gravados (embora não necessariamente inventados) na hora, como o/a espectadora-participante pode verificar em sua tela de WhatsApp. Se a proposta de Loza/Gaggini se assemelha à áudio-leitura de um romance, a proposta do Grupo Magiluth de fato evoca a situação de um estar juntos para contar e ouvir a história. Ou seja, no primeiro caso, o fetiche da voz de atores globais é o fetiche que se compra, como se fosse um boneco inflado sobre o qual age a minha fantasia, enquanto a proposta do Grupo Magiluth é comprar o processo do encontro, a performatividade da contação, de encher o boneco juntos.
} 
No caso da performatividade, isso se realiza por meio do controle de nossa participação enquanto agente da narração.

O que nos é sugerido nessa performatividade de contação de história, então, é abrir-nos para as afeições da ficção, onde possivelmente se manifestará uma abertura eventual para elementos de alteridade no interior da ficção que constituíram momentos provocadores para que acontecimentos irrompessem em nossa imaginação. Na verdade, se trataria de propor uma ficção desconcertante e não reconfortante, mas que não obstante libertaria não só respostas de fechamento interno perante o possível desconhecido, mas reverberações de encanto com essas possibilidades desconhecidas até esse momento ou ainda não experimentadas em sua completude. Essa, ao menos, seria a tarefa para uma ficção que se pretende como acontecimento. Uma tarefa que se apresenta obviamente como tarefa cultural simbólica e menos como desafio de provocação perante diversos espectadores empíricos reais.

Nesse contexto, a dimensão ficcional de Tudo que coube numa VHS pode ser resumida de duas maneiras: a partir do ponto de vista do personagem, como enredo, e também como um arcabouço ficcional mais distanciado, cujo centro não é a singularização de um encontro amoroso, mas um arranjo compositivo realizado pelos artistas do Grupo Magiluth, no qual eles evocam como experiência temática central a maneira como a composição ficcional configura a perda abrupta (morte, sumiço) de uma pessoa amada. A diferença está no grau de artificialidade e de consciência compositiva que cada possibilidade evoca, e também no grau de identificação que cada uma provoca. Enquanto o primeiro se oferece a uma identificação mais melodramática com o personagem, o segundo, por focar na estrutura da ficção, se oferece a uma percepção mais impessoal e sintomática, cujo referencial não é uma possível verossimilhança com uma vida empírica, mas uma constelação cultural coletiva: como a linguagem desse trabalho evoca os afetos? Como sugere aos/às espectadores/as lidar com memórias de perda e de dor?

Na prática, ambas as versões se entrelaçam na oferta, por parte do personagem narrador, de configurar essa contação como um ritual de despedida para esse você, a fim de assegurar "que alguma coisa dentro de você continue 
pulsando, continue viva."30 Por um lado, propõe-se a necessidade de uma cura renovadora perante a separação forçada, a chamada morte dessa pessoa amada, mas por outro lado, chama atenção a tentativa de atenuar já de antemão o impacto da separação por uma espécie de cumplicidade : "Morri, mas tudo bem, a gente sabia que ia ser assim, né, que eu iria, e ficaria só você, antes de nossa última cerveja". ${ }^{11}$ Por um lado, morte e renascimento da vitalidade como dois acontecimentos, e por outro lado, a quase banalidade de um amortecimento afetivo que se baseia num reconhecimento intelectual compartilhado de que na verdade nada aconteceu, que a relação se desfez porque isso era seu rumo. Essa tensão entre os dois aspectos retoma e duplica no campo da ficção a tensão entre a performatividade potencialmente dialógica e seu controle concreto. Desse modo, repete no campo ficcional o destino da performatividade que acaba realizando de fato uma cena do Um, embora enunciasse que busca a cena do Dois.

O drama cultural coletivo que essas duas cenas apresentam se articula na tensão de que por mais que haja mudanças no plano individual das paixões e separações, essa relação não passa de uma sequência que deixa intocada a lógica cultural coletiva da cumplicidade anestesiada, do isolamento como normalidade ("Morri, mas tudo bem”) com qual pessoas supostamente maduras se conformam sem grande alarde. Assim encontramos duas maneiras de deixar-se atravessar pela ficção desse amor: por um lado pelas lembranças que constituem a história desse casal específico (uma história cujo caráter acontecimental não está muito aprofundado, mas que está evocado, sim), e por outro lado, pela sintomática cultural que se expressa na dificuldade de lidar com essa história de outra maneira a não ser de uma separação forçadamente consensual ("a gente sabia", mas apenas um tem o direito à voz).

Nesse caso, a tensão entre ambos os aspectos constituiria a cena do verdadeiro conflito. Claramente, a duplicidade desses elementos (de provocar uma cena do Dois e de controlar ou atenuar esse diálogo numa cena consensual,

30 Vídeo recebido pelo autor do artigo, XX, no dia 26 de outubro, às 19h59, 0'50" a 1'11". GRUPO MAGILUTH. Tudo que coube numa VHS. Material enviado no momento da apresentação, arquivo pessoal dos autores deste artigo, não publicado. 2020.

${ }^{31}$ Ver posição 0'4"-0'25" desse primeiro vídeo enviado aos autores. GRUPO MAGILUTH. Tudo que coube numa VHS. Material enviado no momento da apresentação, arquivo pessoal dos autores deste artigo, não publicado. 2020. 
uma cena do Um) tanto no campo performativo quanto no campo ficcional indica como acontecimento central latente não o encontro amoroso entre os dois personagens, mas a constelação cultural: o conflito entre uma vontade de sentir profundamente o risco da paixão e uma crença ("a gente sabia”) de que o desfazer do amor não é um desastre (porque não é vivido como fidelidade a um acontecimento que a separação tornaria um desastre!). A possível relação desse conflito com as lógicas culturais afetivas de nosso tempo não é acidental. Corresponde com aquilo que Žižek chama a normalização da violência de se apaixonar (2017, p.47) e Badiou a "concepção securitária” (2013b, p. 11) da vida, como se a tarefa principal para nossa maneira de relacionarmos com os afetos seria não perder-se no risco inerente do "acontecimento", que é, por um lado, ser profundamente ferido em nossa auto-suficiência e, por outro, ficar impérvio perante o chamado pela transformação de si mesmo/a e do mundo, o que é a função principal de um acontecimento.

A composição ficcional de Tudo que coube num VHS configura um mundo em que o risco de ser desestabilizado e transformado é contornado de antemão. Em termos poéticos, o que marca essa narrativa de morte ou separação contida é a ausência de um clímax e de uma catarse, de uma repetição da memória que possa levar a sério a história amorosa naquilo que ela prometia realizar: uma desestabilização do eu centrado em si e seu prazer para criar um Dois cujo motor propulsor é o jogo dessa desestabilização. É essa desestabilização em direção à alteridade que nossa cultura - na leitura que esse trabalho implicitamente faz dela - se recusa a atravessar em sua radicalidade. Mas o preço que se paga pela afirmação que ambos sabiam que essa morte ia acontecer, e pelo conforto afetivo que esse reconhecimento pode oferecer, é uma vida individualista, ensimesmada, reconciliada fatalisticamente com o próprio isolamento, ou como canta Land of Talk na música final em It’s okay. "Todos nos sentimos deixados para trás/às vezes, quando crescemos." 32 Em outras palavras, esse problema que possui fortes aspectos sociais e estruturais está, na perspectiva em que o trabalho o apresenta, sendo privatizado (ou abordado apenas em sua dimensão privada).

${ }^{32}$ Leia-se no original: "We all feel left out// sometimes growing up.". YOUTUBE. Canal Saddle Creek. Videoclip de Land of Talk. It's Okay. Disponível em https://www.youtube.com/watch?v=m53--yTPQNk Acesso em: 25 mai. 2021. 
O que aparentemente falta nesse processo de luto, portanto, são os momentos de separação profundamente dolorosos, momentos de negação, de revolta e de resistência, que reconhecem as contradições dessa cena do Dois, desse pertencimento na diferença ${ }^{33}$ para ou lutar exitosamente contra o impulso da separação ou para chegar por meio do processo de luto também na construção de uma personalidade e de uma visão de mundo que se mantém fiel ao acontecimento inicial que é o apaixonar-se por essa pessoa outra. Ou seja, manter viva uma consciência de que o maior desastre não é separar-se nem institucionalizar a chama da paixão num casamento, mas a incapacidade de perceber e manter viva em cada uma das decisões o chamado do acontecimento inicial: de viver uma vida fiel à instabilidade transformadora acontecimental da paixão amorosa. Se em nível de performatividade o trabalho evoca mais um pseudo-encontro, ou um encontro de cunho securitária, em nível ficcional, as mensagens configuram um processo que se aproxima a um pseudo-luto e caracteriza a ficção amorosa menos como uma história de fidelidade para com o acontecimento de um encontro amoroso apaixonante, mas como uma normalização reativa e uma "reintegração ao campo predominante"34 da subjetividade contemporânea "capitalista" (infinitamente instável, emocionalmente instrumental, e solipsista). A própria montagem se coloca como uma resposta que obscurece a natureza do evento amoroso, que torna visível a absoluta necessidade de vivenciar não só as instabilidades e contingências como

\footnotetext{
${ }^{3}$ A mesma ausência marca o texto Filtro Solar de Pedro Bial, mencionado nas reminiscências das figuras ficcionais. A falsa inclusividade dessa letra se revela quando não focamos nos conselhos que ela enumera (em sua grande maioria confluindo para um hedonismo e um imaginário consumista individualista que revelam a classe média alta brasileira como seu ninho e público-alvo), mas naquilo que as palavras não mencionam (embora forme o contexto social dos conselhos): as desigualdades econômicas brutais, os conflitos raciais e a discriminação das minorias em geral (presentes claramente na linha Brothers and Sisters da música original Everybody's Free (To Feel Good), citada no interior da versão de Bial, e que evidencia que no caso da música americana, o título não é um slogan hedonista, como usado no texto de Bial, mas um grito de autoafirmação da comunidade negra desvalorizada). Youtube. Canal de Rozalla. Everybody's Free (To Feel Good) Disponível em: https://www.youtube.com/watch?v=LM9kN4v065Y\&list=PL-LMmfP4dd59LCfMi8z3A3s-hFjlfWt9c Acesso em: 26 nov. 2021.

${ }^{34}$ Essa é uma das possibilidades de responder ao acontecimento, conforme Žižek (2011, p.384), que se baseia em suas seis respostas possíveis no esquema de Badiou (2009, p. 62) composto por apenas quatro possibilidades: a resposta interessada numa ação fiel, ou uma ação reativa ao evento e à fidelidade perante ele, ou obscurecendo a natureza evento, e por último buscando repeti-lo numa espécie de ressureição do
} evento. 
expressão de uma pulsação vital, mas também o pertencimento e a entrega a uma alteridade.

Apesar de evocar prazeres de trocas leves nos jogos de flertar e de conjurar uma proximidade numa voz que provém da memória desse efêmero outro, cada personagem, e nós juntos, ficamos centrados/as em si, ao mesmo tempo em que sentimos o desejo pelo acontecimento do encontro e da cena amorosa do Dois. O trabalho ensaia uma entrega profunda e o risco da catarse - que exige daqueles que amam afastar-se radicalmente de si mesmo - para logo recuar e afirmar o apego a uma cena do Um. Não nos parece mera coincidência que a música final nos apresenta dois adultos agora supostamente maduros em sua isolação e aconchegados na esperança por um outro abstrato: "Alguma coisa em sua voz,/ acende um pouco de esperança/ Vou esperar por esse ruído/ sua voz se torna meu lar." ${ }^{35} \mathrm{Na}$ maneira como lida com os afetos amorosos, a própria apresentação artística se torna esse ruído humano que acaba nas condições sociais dadas por nos aprisionar na esperança abstrata de que essa arte possa tornar-se nosso lar.

\section{Considerações finais}

Diferente da reação entusiasmada de muitos espectadores que deram seu depoimento nas redes sociais do grupo (com termos bastante gerais como "sensível", "poético" ou "incrível”), não ficamos tão eufóricos ao assistir o trabalho. Sentimos seu efeito sedutor, até encantador, a sua sensibilidade para com situações cotidianas, mas não ficamos tão comovidos (embora felizes que o trabalho tenha permitido ao Grupo Magiluth continuar existindo, continuar com uma sede e poder imaginar um futuro próximo para sua produção ao vivo). Pois, mesmo que concordemos com essa parcela de público de que o trabalho mostra uma sensibilidade afetiva e certo esmero artístico, bem como uma fluidez técnica no uso dos recursos comunicativos, nós não nos sentimos tão impactado por essas qualidades perante o gesto “ideológico” da construção: a intenção

${ }^{35}$ Leia-se no original: "Something in your voice,/ sparks a little hope / I'll wait up for that noise/ your voice becomes my home”. YOUTUBE. Canal Saddle Creek. Videoclipe de Land of Talk. It's Okay. Disponível em https://www.youtube.com/watch?v=m53--yTPQNk Acesso em: 25 mai. 2021. 
reconfortante e conciliadora que o trabalho ativa em seu arranjo compositivo. É compreensível que nesse momento da pandemia esse gesto consolador sobressai a usos mais críticos ou mais subversivos da proposta de experimentar um encontro. Entretanto, por mais que a necessidade de ser amado seja uma constante humana fundamental, ${ }^{36}$ sentimos que a estrutura do trabalho e suas reações documentadas provocam uma outra questão mais básica ainda: de que concepção de amor e de amar estamos falando? Que concepção estamos buscando? Uma pergunta, que poderia ser estendida também para termos como "intimidade" ou "encontro". Trata-se de uma questão que necessita uma resposta não somente em termos pessoais, mas principalmente em termos culturais.

Nesse sentido, exatamente na oscilação entre, por uma lado, a evocação de um acontecimento, que evidencia um descontentamento implícito com um status quo, e por outro lado, o controle da performatividade e da ficção para que o acontecimento não possa ameaçar o andamento da cena e da ficção evocados, Tudo que coube numa VHS pode ser lido como sintoma cultural da contemporaneidade: há presença de conflitos, mas uma ausência de um confronto real; nos deparamos com a presença de um desejo pelo encontro, mas a ausência de uma coragem de realmente explorar seu potencial transformador performativo, ficcional e social. Em suma: a presença de um descontentamento e de uma busca por uma vida mais satisfatória, mas a ausência da crença (e consequentemente da coragem) de que haja alternativa. Em termos cênicos, a presença de elementos dramáticos, mas a ausência de clímax ou desenlace e de transformação qualitativa. Articulam-se apenas variações quantitativas. Ou, pensando o trabalho como "performance narrativa", trata-se da evocação de momentos performativos, mas na ausência do impulso implícito e originário da performance que é produzir um confronto doloroso não só entre artista e espectador/a, mas do/da espectadora consigo mesmo/a.

Nesse contexto, é um resultado relevante que o trabalho oscile entre protesto e reconforto, revolta e conformismo estrutural, resignação e entusiasmo.

${ }^{36}$ Como salienta Sigmund Freud, em Inibição, sintoma e angústia, quanto à angústia de desamparo do bebê recém nascido, "o fator biológico dá origem às primeiras situações de perigo e cria a necessidade de ser amado, que jamais abandona o ser humano” (Freud, 2014, p.75). 
Nesse sentido, ele pode ser comparado a fenômenos pop como o movimento disco dos anos 70 e 80 (que atualmente vive um revival) ou ao movimento romântico na leitura que oferecem Löwy e Sayre (2015). ${ }^{37}$

Igual a esse e outros movimentos de cultura pop, Tudo que coube numa VHS é marcado pelo modo de produção capitalista. A prometida intimidade pessoal acontece, por exemplo, num ritmo extremamente mecânico, de trinta em trinta minutos, o que dá ao espetáculo uma dimensão de linha de produção. Em outras palavras, encontramos no interior do espetáculo, na performatividade de sua produção, por um lado, a confissão de participar dos efeitos de uma máquina capitalista, e por outro lado, na temática e no material apresentado como corpo do espetáculo em si, um protesto contra essa máquina e seus efeitos, mesmo que em nenhum momento seja dito e exposto a palavra e a realidade capitalista.

É exatamente essa contradição, essa dialética de participar de uma estrutura de produção e apresentação mercantil e simultaneamente de produzir a impressão de uma singularidade no encontro afetivo, que se coloca como sintoma cultural e social. Pois não é que encontramos nessa contradição, nesse disfarce da dimensão mercantil atrás de uma sedução afetiva supostamente singularizada, o alívio que um fingido encontro amoroso nos dá na ausência de sua possibilidade real? Encontramos nesse conforto fabricado tanto um sujeito resignado quanto um sujeito apegado a uma utopia abstrata, embora não saiba exatamente como lutar por sua realização.

Para liberar o efeito acontecimental de uma linguagem poética talvez seja antes de mais nada necessária uma firme decisão de identificar na própria linguagem o perigo de cooperar com aquilo que se queira criticar. ${ }^{38}$ Para além de

\footnotetext{
${ }^{37}$ Ver, por exemplo, a matéria de Madison Vain na versão online da revista Esquire do 21 de outubro de 2020 sobre o novo álbum de Kylie Minogue. Nela, Kylie afirma que a música Disco é três minutos de escapismo e euforia que as pessoas necessitam nessa sociedade; uma música que faz chorar não apenas por tristeza, mas por sentir nela uma faísca de esperança. Encontramos nessa descrição o reconhecimento implícito de que essa música é um acontecimento que sabe de antemão de sua impossibilidade de se realizar plenamente e que por isso escolha o caminho escapista. E nesse escapismo consegue preservar uma força latente de protesto e de crítica. Disponível em https://www.esquire.com/entertainment/music/a34369549/kylie-minogue-disco-album-interview-2020/ Acesso em: 26 nov. 2021. Uma ambivalência que está presente na música Pop, e que se articula como problemática na arte ocidental desde o começo da eclosão maciça do capitalismo na revolução industrial (ver Löwy e Sayre, 2015).

${ }^{38}$ É útil aqui lembrar que Walter Benjamin, na Tese VI de suas reflexões Sobre o conceito da história, nos alerta que o perigo fundamental de qualquer narrativa que constrói uma imagem do passado é o de
} 
permitir contagiar-se pelas características ideológicas formais ou temáticas do status quo, é preciso enfatizar e elaborar os caminhos que podem ajudar a superar o status quo. Uma decisão que implica em uma perfomatividade que retoma e reencena o problema para dar-the um outro rumo; ou seja, implica em usar uma linguagem estrutural (poética ou não) de modo claramente não reconciliador. Uma linguagem que intensifica nossa fome e que mais nos mostra do que enuncia para nós que o contrário da vida não é a morte, mas o amortecimento afetivo, a "mortificação" do estar vivo, nas palavras Luiz Antonio Simas e Luiz Rufino (2020). Talvez seja essa uma linguagem na qual a paixão ganha uma concretude que vai além da poetização do sujeito individual único, pois o abre e abre não só para o social, mas até para o cosmos e nele encontra seus impulsos transformadores para configurar o social.

Por vias negativas, a evocação performativa e ficcional de acontecimentos naturais, amorosos e sociais em Tudo que coube numa VHS até pode intensificar nossa fome por esse encantamento. Assim, cabe a nós espectadores/as buscar, a partir do reconhecimento das limitações dessa evocação, maneiras de se mostrar fiel ao chamado desses acontecimentos, de superar essas limitações e de encontrar formas de saciar nossa fome, de dar condições e duração não só ao amor, mas também à ideia de estar juntos no encontro que é um verdadeiro jogo acontecimental da diferença, onde trinta minutos podem se tornar apenas cinco ou alastrar-se para uma infinidade.

\section{Referências}

BADIOU, Alain e TARBY, Fabien. El acontecimiento y la filosofía. Madrid e Buenos Aires: Amorrortu editores, 2013a.

BADIOU, Alain e TRUONG, Nicolas. Elogio do Amor. Trad. Dorothée de Bruchard. São Paulo: Martins Fontes 2013b.

configurá-lo de tal maneira que ela possa se transformar "em instrumento das classes dominantes" (2018, p. 11). Para Benjamin, não basta somente evocar "o momento do perigo" (Benjamin, 2018, p. 11), mas é preciso combater o conformismo, que não é apenas a acédia do coração se não também o desejo de se inserir mesmo que criticamente no status quo. Nesse sentido, por outro ângulo não psicológico, senão social e político, as histórias que não têm fim são aquelas que ainda não encontraram sua resolução social, que ainda não esgotaram seu potencial revolucionária ou, nas palavras de Badiou, seu "procedimento de verdade" para com o acontecimento fundador. 
BAUMAN, Zygmunt. Modernidade Líquida. Trad. Plínio Dentzien. São Paulo: Zahar, 2001.

BENJAMIN, Walter. Sobre o conceito de história. In: BENJAMIN, Walter. O anjo da história. Org. e Trad. João Barrento. Belo Horizonte: Autêntica Editora, 2018.

CUPERTINO, Karine de Oliveira. Um para um: a busca por uma subjetividade dialogada. 2018. Dissertação (Mestrado em Teatro) - Centro de Artes Universidade do Estado de Santa Catarina, 2018. Disponível em http://sistemabu.udesc.br/pergamumweb/vinculos/000050/0000505e.pdf Acesso em: 21 dez. 2020.

DUBATTI, Jorge. Convivio y tecnovivio: el teatro entre infancia y babelismo. Revista Colombiana de las Artes Escénicas, v. 9, n. 44-54, 2015.

DUBATTI, Jorge e MUNIZ, Mariana Lima. Cena de Exceção: o teatro neotecnológico em Belo Horizonte (Brasil) e Buenos Aires (Argentina). Revista Brasileira de Estudos da Presença, Porto Alegre, v. 8, n. 2, p. 366-389, abr./jun. 2018.

FACEBOOK. Perfil do Grupo Magiluth. Postagem de 04 mai. 2020. Disponível em https://www.facebook.com/magiluth/posts/tudo-que-coube-numa-vhsexperimento-sensorial-em-confinamento-um-trabalhocriado/1548813865273505/ Acesso em: 19 nov. 2020.

FACEBOOK. Perfil do Grupo Magiluth. Vídeo do Programa Bom dia Pernambuco. Postagem de 13 jun. 2020. Disponível em:

https://www.facebook.com/watch/?v=2668210176730980

Acesso em: 3 de jan. 2021.

FACEBOOK. Perfil do Sesc Avenida Paulista. Disponível em https://www.facebook.com/sescavpaulista/posts/3037332699647334 Acesso em: 20 jul. de 2020.

FISHER, Mark. Realismo Capitalista: É mais fácil imaginar o fim do mundo do que o fim do capitalismo? Trad. Jorge Adeodato e Maikel da Silveiro Rodrigo Gonsalves. São Paulo: Autonomia Literária, 2020.

FREUD, Sigmund. Inibição, sintoma e angústia: o futuro de uma ilusão e outros textos (1926-1929). Trad. Paulo César de Souza. São Paulo: Companhia das Letras, 2014.

GRUPO MAGILUTH. Tudo que coube numa VHS. Material enviado no momento da apresentação, arquivo pessoal dos autores deste artigo, não publicado. 2020.

JAMESON, Fredric. Postmodernism, or the cultural logic of late capitalism. London \& New York: Verso, 1991.

JAMESON, Fredric. As Sementes do Tempo. Trad. José Rubens Siqueira. São Paulo: 
Ática, 1997.

JAMESON, Fredric. A Cultura do Dinheiro. Ensaios sobre a globalização. Seleção e prefácio de Maria Elisa Cevasco. Trad. Maria Elisa Cevasco e Marcos César de Paula Soares. Petrópolis: Vozes, 2001.

INSTAGRAM. Perfil do ator do Grupo Magiluth Bruno Parmera. Disponivel em https://www.instagram.com/p/Bn4reQqBl6c/?igshid=zllrkk88zm1y Acesso em: 26 de novembro de 2020.

INSTAGRAM. Perfil do Grupo Magiluth. Postagem de 04 mai. 2020. Disponível em https://www.instagram.com/p/B_x7C6jnKZC/?utm_source=ig_embed Acesso em: 17 dez. 2020.

LACAN, Jacques. O tempo lógico e a asserção de certeza antecipada. In: Jacques. Lacan. Escritos. Rio de Janeiro: Jorge Zahar, 1998.

LÖWY, Michel e SAYRE, Robert. Revolta e Melancolia. São Paulo: Boitempo, 2015.

MUK PRODUÇÕES. Amor de Quarentena. Disponível em http://amordequarentena.com/ Acesso em: 08 nov. 2020.

SIMAS, Luis Antonio e RUFINO, Luis. Encantamento: sobre políticas de vida. Rio de Janeiro: Morula, 2020.

SYMPLA. Página do evento "Amor de Quarentena". Disponível em https://www.sympla.com.br/amor-de-quarentena_933338. Acesso em: 08 nov. 2020.

SYMPLA. Página do evento "Tudo que coube em uma VHS". Disponível em https// www.sympla.com.br/tudo-que-coube-em-uma-vhs---2310---20h_988633 Acesso em: 11 nov. 2020.

VAIN, Madison. Kylie Minogue Is Leading a Disco Revolution. Again. ESQUIRE. Disponível em https://www.esquire.com/entertainment/music/a34369549/kylieminogue-disco-album-interview-2020/ Acesso em: 26 nov. 2021.

UBERSFELD, Anne. Para ler o teatro. Trad. José Simões (coord.). São Paulo: Perspectiva, 2005.

YOUTUBE. Canal de Rozalla. Everybody's Free (To Feel Good) Disponível em https://www.youtube.com/watch?V=LM9kN4v065Y\&list=PL-

lMmfP4dd59LCfMi8z3A3s-hFjlfWt9c Acesso em: 26 nov. 2021.

YOUTUBE. Canal do Arte 1. TUDO QUE COUBE NUMA VHS - MAGILUTH | ARTE1 EM MOVIMENTO. Postagem de 21 jun. 2020. Disponível em https://www.youtube.com/watch?v=NyV9Hj_niRo Acesso em: 19 nov. 2020.

YOUTUBE. Canal do ator do Grupo Magiluth Bruno Parmera. Disponível em 
Prometendo a cena online como acontecimento:

https://youtu.be/ccLZYCuhUmA Acesso em: 9 dez. 2020.

YOUTUBE. Canal Saddle Creek. Videoclipe de Land of Talk. It's Okay. Disponível em https://www.youtube.com/watch?v=m53--yTPQNk Acesso em 25 mai. 2021.

ŽlŽEK, Slavoj. Em defesa das causas perdidas. São Paulo: Boitempo, 2011.

ŽIŽEK, Slavoj. Acontecimento: uma viagem filosófica através de um conceito. Trad. Carlos Alberto Medeiros. Rio de Janeiro: Zahar, 2017.

Recebido em: 27/05/2021

Aprovado em: 19/08/2021 